attitudes of health professionals to AIDS care and people with AIDS found that nurses' attitudes became more favorable the more contact they had with AIDS patients, while physicians' attitudes became more negative with greater contact. ${ }^{9}$ The accumulation of evidence, including the results of the study of ambulatory AIDS care published in this issue, points to the considerable potential of nurses to improve quality of care for people with AIDS in all care settings. AIDS care is beset by a multitude of problems and challenges that will not be easily solved. In that light, creating more central roles for nurses would appear to be a feasible way to have more than a marginal impact on the quality of AIDS care.

The Stone et al. paper also provides sobering confirmation of the nation's continuing problems providing satisfactory health care to African Americans, particularly those from poor, urban areas. The increasing dissemination of HIV infection in poor minority populations will pose perhaps the greatest challenge to the organization of appropriate and satisfactory AIDS care in the future. The present restructuring of the health care marketplace in the absence of universal insurance coverage poses new difficulties for vulnerable populations. Even the Medicare program with its universal insurance coverage has not yet been successful in providing care to inner-city black beneficiaries that is comparable to that received by others. ${ }^{10}$ Financing is part but not all of the problem. This study suggests that organizational models of care patterned more along the lines of private-sector medical group practices or HMOs and including primary nurses offer the possibility of more satisfactory care than has been traditionally available in hospital-based clinics, which have long been the only choice for the inner-city poor.-Linda H. Aiken, PhD, Center for Health Services and Policy Research, School of Nursing, and the Department of Sociology, University of Pennsylvania, Philadelphia, PA 19104-6096

\section{REFERENCES}

1. Stone VE, Weissman JS, Cleary PD. Satisfaction with ambulatory care of persons with AIDS: predictors of patient ratings of quality. J Gen Intern Med. 1995;10:239-45.

2. Reputations are made of these. U.S. News World Rep. 1990;Apr 30:83.

3. Aiken LH, Lake ET, Semaan S, et al. Nurse practitioner managed care for persons with HIV infection. Image: J Nurs Scholarship. 1993;25:172-7.

4. Office of Technology Assessment. Nurse Practitioners, Physicians Assistants and Certified Nurse-Midwives: A Policy Analysis (Health Technology Case Study No. 37). Washington, DC: U.S. Government Printing Office, 1986.

5. Brown SH, Grimes DE. Nurse Practitioners and Certified NurseMidwives: A Meta-Analysis of Studies of Nurses in Primary Care Roles. Washington, DC: American Nurses Foundation, 1993.

6. Fox RC, Aiken LH, Messikomer CM. The culture of caring: AIDS and the nursing profession. Milbank Q. 1990;68(suppl 2):226-56.

7. Cooke M. Sande MA. The HIV epidemic and training in internal medicine. N Engl J Med. 1989;321:1334-8.

8. Aiken LH, Smith HL, Lake ET. Effects of organizational innovations in AIDS care on "burnout" among urban hospital nurses. Cincinnati. $\mathrm{OH}$ : presented at the Annual Meeting of the American Sociological Association, 1991

9. Colombotos J, Messeri P, McConnell MB, Elinson J, Gemson D, Hynes M. Physicians, nurses, and AIDS: findings from a national study. Rockville, MD: Agency for Health Care Policy and Research (publ. no. 93-0043), Aug 1994.

10. Physician Payment Review Commission. Monitoring Access of Medicare Beneficiaries (Report to Congress No. 92-5). 1992.

\title{
To Screen or Not to Screen:
}

\section{What is the Question?}

E lsewhere in this issue of the Journal, Brett analyzes current controversies in breast and prostate cancer screening and concludes that we need a single set of national screening recommendations that would be recognized as the "basic" standard of care by patients, physicians, and payers. ${ }^{1}$ He argues that the U.S. Preventive Services Task Force should make these recommendations because this group is relatively free of conflicts of interest and uses conservative, evidence-based decision rules.

Leaving aside the question of how one might vest any group with such supreme authority, Brett's conclusion-based on the criteria of objectivity and methodologic rigor - makes sense only if one believes that these screening controversies are largely over the proper interpretation of imperfect data. Very different conclusions result if one believes, as I do, that the interpretation of the scientific evidence is perhaps the least controversial aspect of these debates. Most, but certainly not all, voices in these debates agree that there is inadequate evidence to support prostate-specific antigen (PSA) screening for most men or mammography for women under the age of 50 years - the controversy is whether to screen in the absence of such evidence. To many thoughtful individuals who disagree with the Task Force recommendations, the lack of such evidence is merely a "type II" error to be corrected by future research and reflects the limitations of older technology and treatments.

My alternative vision of these controversies is that they are mostly fueled by competing beliefs, perspectives, values, and interests. Looked at this way, any proposed solution must provide a way to balance different 
beliefs, perspectives, values, and interests as much as relying on evidence-based methods and individuals without conflicts of interest.

Let me use the two screening controversies to sketch some of the underlying factors that need to be balanced. Many clinicians and patients support screening mammography for women under 50 because it seems only logical that such a practice should save or extend some lives. Breast cancer affects women in their 40s. Mammography should be able to identify at least some small cancers that have malignant potential but have not yet metastasized. For many patients and clinicians, extrapolating from no good evidence to not screening means suspending an entire belief system about cancer. Not to screen means accepting the idea that women in their 40 suffer breast cancers that are extremely idiosyncratic, either so "good" or so "bad" that early detection adds little to eventual outcome (in addition to more understandable factors such as age-related diagnostic accuracy and low prevalence). In other words, an important dividing line in this controversy is whether one is willing to suspend belief in the dominant ontologic model of disease - that breast cancer has an orderly and predictable natural history based on stage and grade in affected women-and accept a more idiosyncratic view of disease.

A related tension concerns the meaning of the word cancer. The PSA controversy is largely over the prognosis and meaning of prostate cancer. especially very small and localized cancers discovered unexpectedly during transurethral prostatectomy (TURP) or by blind or ultrasound-guided biopsy. Why find these cancers at all if existing treatment is on average no better than leaving things alone? Some lay people - and many doctors-might make different decisions if the word cancer were not used in this context, since it is hard to reconcile cancer with a low probability of ever causing serious morbidity or mortality.

The conflict over these screening recommendations also embodies a perspectives clash that is sometimes mistakenly reduced to one between objective experts making evidence-based health policy and clinicians who must deal with real-world patients and the unscientific factors involved in their care. I say "mistakenly" because the perspective difference is not simply a matter of objectivity vs subjectivity, science vs emotion. Rather, there are structured differences between the group and individual perspectives in the assessment of risk and benefit that may lead to different but equally valid conclusions.

Simply put, the individual perspective is much more sensitive to the laws of small numbers - what is best for a decision maker looking at policy based on many rolls of the dice is not the same as what is best for someone who has only one chance to play. ${ }^{2}$ Patients are not necessarily being irrational when they choose radical prostatectomy to remove a very small cancer, knowing the lack of demonstrated efficacy of prostate surgery and the high probability of impotence and incontinence. Since they make this decision only once, the opportunity to avoid an unlikely but greatly feared outcome, i.e., premature death from prostate cancer, may be preferable even if the iatrogenic risk is "on average" likely to lead to greater harm. From the policy maker's perspective, this decision is in essence repeated many times, allowing the occasional gain in life expectancy to be drowned out by more prevalent iatrogenic harm.

Screening controversies also arise from a clash between scientific and consumer values. The rise of the consumer ethic in medicine has had profound effects, from the acceptance of the principle of informed consent to the current wisdom that "the market" will solve our health care access and cost problems. But it has also led to conflict over whether health services should respond to consumer demand or to scientific opinion about their effectiveness. For example, it might make sense for a managed care organization to offer screening mammography to women in their 40 s if it results in an improved perception of health and security among its members. On what basis should an expert panel overrule an economic calculation based on consumer demand and cost? And even if one agreed that biomedical experts should properly assess the effectiveness of different health services, what level of cost-effectiveness to pay for is most certainly a matter of perspective-the payer, the individual, or the larger community-especially when the evidence suggests that screening works, but is expensive.

A related conflict pits a positivist view of scientific and technologic progress against an equally compelling view of scarcity and the need to conserve limited resources. In the past few decades, the biomedical establishment has encouraged the public to enlist in the war against cancer by approving monies for biomedical research, reducing risky behaviors, and complying with screening recommendations. More recently, the same public has been told that the cost of health care--including wasteful and unproven cancer therapies and prevention practices-threatens our economic security and competitiveness. In retrospect, one can argue that cancer researchers and oncologists may have oversold what they can offer in the war on cancer. What is harder to appreciate is the way health service researchers, epidemiologists, and others may be presently guilty of overselling outcomes research, evidence-based policy decisions, and quality measures as a means of containing costs and figuring out what practices are effective. It is wrong to view the latter group as "objective" while labeling radiologists, surgeons, oncologists, and lay disease advocates as biased. Each group's point of view is influenced by ideology, status, and economics.

Finally, we would be remiss if we framed the debates about disease prevention simply in terms of whether to do $\mathrm{X}$ or $\mathrm{Y}$ without recognizing that the fact that the " $\mathrm{X}$ or $Y$ issue" is on center stage-rather than other is- 
sues-and is itself a policy problem. The PSA controversy exists because of the rapid diffusion of the PSA test. Should this test have been developed in the first place? In more general terms, should we assert some control over our ever-growing technologic capacity to define new diseases and incipient risks? The value we place on technologic innovation (e.g., human genomic research), the large market for new risks and diagnoses, our desire for certainty, and our decentralized, shieldedfrom-cost decision making have and will inevitably lead to many similar debates about screening for other diseases. ${ }^{3}$ The questions we raise are as much a product of unbridled technology development as they are about evidence-based technology assessment.

We might similarly ask why we focus so much attention on the issue of mammography for women in their 40 s when an epidemiologically more important issue is the poor compliance among women aged 50 through 59 where efficacy has been demonstrated. Or we might ask why there is no raging controversy over screening $\mathrm{x}$-rays and sputum cytology for detecting lung cancer among smokers. The evidence for screening smokers is as unconvincing as the evidence for screening women under 50 with mammography. ${ }^{4}$ The answer probably has a lot to do with our belief that smokers are responsible for cancer while women are innocent victims. Whether this is true, the point is that values not only fuel the specifics of conflicts but help determine what gets focused on in the first place. To merely accept the most public and prominent prevention controversies as the agenda for an expert panel is as myopic as framing them solely as problems of data interpretation.

It is easy to view these prevention controversies as hopelessly unresolvable. But the outline of a solution suggests itself from the analysis of underlying factors. We should be more cautious about the objectivity of health service researchers and the reach of evidence-based appraisal of the literature. When evidence conflicts with basic models and meanings of disease, we need to recognize and accommodate the ensuing cognitive dissonance. Recommendations to clinicians and patients need to be flexible, not because of mystical qualities of the doctor-patient relationship, but because individuals necessarily approach decisions differently than do policy makers. We need to remember that it is as much of a policy issue to decide which questions get asked as it is to find answers to them. Making difficult decisions requires evidence-based information, but it also means balancing competing beliefs, perspectives, values, and interests. If we are to look to some central authority for help, it should adequately represent groups with a stake in disease prevention-patients, clinicians, researchers, and payers. In the end, the best recommendations will be those that take into account the complex ideologic, social, and political forces that shape our response to specific health issues.-Robert Aronowitz, MD, University of Medicine and Dentistry of New Jersey/ Robert Wood Johnson Medical School, Camden, NJ 08103

\section{REFERENCES}

1. Brett A. The mammography and prostate-specific antigen controversies: implications for patient-physician encounters and public policy. J Gen Intern Med. 1995;10:266-70

2. Asch DA. Choices for individual patients vs. groups [letter]. N Engl J Med. 1990;323:922.

3. Aronowitz RA. Trouble in prevention. J Gen Intern Med. 1994;9: 475-8.

4. Evanoff B, Checkoway H. Weiss N. Rosenstock L. Periodic chest $\mathrm{x}$ ray for lung cancer screening: do we really know it's useless? [abstractl. Presented at the Robert Wood Johnson Foundation Clinical Scholars Meeting, Ft. Lauderdale. FL, 1993. 